\title{
Functional MRI reveals expert-novice differences during sport-related anticipation
}

\author{
Michael J Wright ${ }^{\mathrm{a}}$, Daniel T Bishop ${ }^{\mathrm{ab}}$, Robin C Jackson ${ }^{\mathrm{bc}}$, and Bruce \\ Abernethy ${ }^{\mathrm{c}}$.
}

${ }^{\mathrm{a} C e n t r e}$ for Cognition and Neuroimaging, Brunel University, Uxbridge, Middlesex UB8 3PH, UK.

${ }^{\mathrm{b}}$ Centre for Sports Medicine and Human Performance Brunel University, Uxbridge, Middlesex UB8 3PH, UK.

Institute of Human Performance, University of Hong Kong, Pokfulam, Hong Kong

${ }^{1}$ Corresponding author address as above
Email: michael.wright@brunel.ac.uk

The work described in this paper was substantially supported by a grant from the Research Grants Council of the Hong Kong Special Administrative Region, China Project No. HKU 7400/05H.

Running head: fMRI analysis of anticipatory skill

Body text $=14379$ characters including spaces. Plus two tables and one figure at $1625=19254$ 


\section{Abstract}

We examined the effect of expertise on cortical activation during sports anticipation using fMRI. In Experiment 1, while recreational players predicted badminton stroke direction, the pattern of active clusters was consistent with a proposed perception-of-action network. This pattern was not replicated in a stimulus-matched, action-unrelated control task. In Experiment 2, players of three different skill levels anticipated stroke direction from clips occluded either $160 \mathrm{~ms}$ before or $80 \mathrm{~ms}$ after racquet-shuttle contact. Early-occluded sequences produced more activation than lateoccluded overall, in most cortical regions of interest, but experts showed an additional enhancement in medial, dorsolateral and ventrolateral frontal cortex. Anticipation in open-skill sports engages cortical areas integral to observing and understanding others' actions; such activity is enhanced in experts.

Keywords: fMRI; sport; perception; action; action observation; anticipation; expertise; skill 


\section{Introduction}

Research using fMRI in humans has identified cortical networks that mediate the perception and interpretation of body actions, and we propose that these systems have a critical role in expert performance in time-constrained sports tasks. The observation of body movements activates a network of brain areas including ventral posterior inferior frontal gyrus, dorsolateral premotor cortex, rostral inferior parietal lobule, intraparietal sulcus, dorsal precuneus and superior temporal sulcus [1-4]. In a previous fMRI study of anticipatory skill in which observers viewed brief video clips of a tennis player serving the ball, we found enhanced activity in inferior parietal lobule and inferior frontal gyrus but not in superior temporal sulcus or MT/V5 during anticipation of serve direction relative to observation of between-play body movements [5].

Recent fMRI studies have demonstrated expertise effects in a range of perceptual-motor skills, including imitation of hand actions (guitarists) [6], motor imagery [7], learning of action sequences (pianists) [8] and action observation (dancers) [9]. In these studies, experts showed increased activation compared with novices in the aforementioned cortical network, but the regions involved vary according to the nature of the task. For example, expert ice-hockey players show greater fMRI activation than novices for hockey-related action sentences in language areas as well as action-related areas [10]. Expert golfers [11] and archers [12] show decreases in activation of actionrelated areas relative to novices during their pre-shot focusing routine. In the present study we examine neural activation during a badminton anticipation task that has yielded significant expert-novice differences in performance data [13].

In behavioural studies of anticipatory skill in sport, experts are consistently superior in using early information from the body kinematics of an opposing player [13- 
16]. Moreover, a behavioural and TMS study of expert basketball players showed that motor, rather than perceptual expertise per se was crucial for anticipation performance [17]. In the present study we used a temporal occlusion method [13-15, 17] to vary the timing of available kinematic information relative to the racquet-shuttle contact in a badminton task. Specifically, we tested the hypothesis that the level of temporal occlusion (early vs. late) and the level of playing expertise (expert vs. novice) both modulate the BOLD response within brain areas subserving the perception and understanding of bodily actions [1-5].

\section{Methods}

Participants: Eight recreational badminton players participated in Experiment 1, and 37 players ranging in ability from novice to international level took part in Experiment 2; all had normal or corrected-to-normal vision. This research was approved by Brunel University Research Ethics Committee and was in accordance with the Declaration of Helsinki; participants gave informed written consent.

Stimuli and design: In Experiment 1, continuous fMRI data was acquired as participants viewed $160 \times 1.76 \mathrm{~s}$ video clips of an opposing badminton player striking the shuttlecock to four regions of the court (supplemental digital content 1 shows an example clip as used in experiment $1 \& 2$ ). Participants pressed one of three buttons, during a 2.24 s luminance-matched screen following each clip, to estimate the side of the court (left/right) to which the shot was directed or to indicate a no-shot control sequence. Every block comprised 5 video clips and 5 blank intervals. There were four block conditions: late occlusion, in which the action of each clip was terminated 80ms after racquet-shuttlecock contact; early occlusion, terminated $160 \mathrm{~ms}$ before racquetshuttle contact; no-shot motion control (mctrl) comprising clips of between-play 
movements; and no-shot stationary controls (sctrl) - freeze-frame clips of the same duration. Participants also undertook a visuospatial (action-unrelated) control task in a separate run, with task order counterbalanced. No-shot blocks for the visuospatial task were the same as described above, but in both early- and late- occlusion blocks, $50 \%$ of all video clips for any given trial type were mirror-reversed (random order). The task was to indicate by a left or right button press on which side the racquet was held, as viewed by the participant. Although no anticipation of stroke direction was required, and indeed, no analysis whatsoever of the action, the kinematics of the stimuli (save for the mirror reversals) and the button press choices (left, right, no-shot) were identical to the anticipation experiment.

In Experiment 2, eight national/international badminton players, 13 club/county players, and 16 novices performed the anticipation task only. Expertise was defined as competitive level with reference to UK league and club designations: novices included recreational and infrequent players. Rather than a two-choice judgment of direction, they made a four-way judgment: left near court, left far court, right near court, or right far court. Temporal occlusion conditions and motion control stimuli and responses were the same as for Experiment 1. Percentage correct responses were recorded for each occlusion condition in addition to fMRI data.

An optic-flow type stimulus consisting of random dot patterns was used to localise visual motion-specific areas in each individual's brain. Incoherent random motion alternated every $15 \mathrm{~s}$ with a complex but coherent flow pattern [18]. The design consisted of 2 block conditions (coherent, incoherent) and 10 repetitions of the stimulus cycle. Participants viewed a central fixation point that randomly changed colour at $1 \mathrm{~Hz}$, 
whilst performing a colour-counting task to aid fixation and to provide a constant attention load.

Data Acquisition: Brain images were acquired with a 3T MRI scanner (Magnetom Trio, Siemens, Erlangen, Germany) equipped with an 8-channel array headcoil. Functional images of the entire brain were acquired with a standard gradientecho, echoplanar sequence (TR 3000ms, 41 slices, voxel size 3 × 3 × 3 mm, 64 x 64 matrix). A whole brain anatomical scan (1 x 1 x $1 \mathrm{~mm}$ voxel size, MP-RAGE, Siemens) was also acquired.

Data Analysis: Pre-processing of the data was performed using SPM2 (http://www.fil.ion.ucl.ac.uk/spm/). Each EPI volume was realigned to correct for head motion, and structural and mean functional images were co-registered. To permit group data analysis, functional and structural images were spatially normalised to the MNI template. Spatial smoothing with a 3D Gaussian filter of FWHM 6 mm, convolution with modelled HRF and high-pass filtering of the time series preceded analysis of individual data: t-contrasts between the block conditions, were thresholded at $P<0.05$ FWE corrected, for each participant. These contrast values were entered into second level, random effects group analysis. Probable Brodmann areas (BA) were identified using the WFU PickAtlas Talairach Daemon at $5 \mathrm{~mm}$ range with MNI coordinate conversion $[19,20]$. Middle temporal visual areas were localised with the localiser tcontrast coherent - incoherent, thresholded at $P<0.05$ FWE to provide a well-defined isolated cluster in the occipital-temporal junction of each hemisphere.

\section{Results}

Experiment 1. The purpose was to compare the anticipation and visuospatial tasks, and to identify regions of interest (ROIs) for the second experiment, which in turn 
was designed to examine the effects of temporal occlusion and expertise. Since temporal occlusion was not a key variable for Experiment 1, data from the early and late conditions were combined, and an overall t-contrast, shots - mctrl was computed, i.e. $($ early + late $) / 2-$ mctrl. Significant clusters in the group analysis are shown in Figure 1 for the anticipation (green) and visuospatial (red) tasks. Table 1 shows coordinates of primary peaks in these clusters. Both tasks produced activation in the occipital-temporal junction, with incomplete overlap. Whereas in the visuospatial control task, shots-mctrl activates visual cortex (BA18) it does not do so in the anticipation task. The difference may be due to reduced motion adaptation when $50 \%$ of stimuli are mirror-reversed and / or to a top-down influence on visual cortex. The most striking point is that there is strong engagement in the anticipation task of areas in parietal and frontal cortex but apart from a small common area of activation in dorsolateral premotor cortex (BA6), the visuospatial task does not significantly engage these areas. Most of the areas activated preferentially in the anticipation task are known from previous studies of action observation [1-5].

\section{Table 1 and Figure 1 Near Here}

Experiment 2. Behavioural accuracy of prediction of the direction of a stroke was significantly above chance $(25 \%)$ for novice, intermediate and expert groups on both the early- $(33.9,35.9,44.8 \%)$ and late- $(71.8,90.6,94.6 \%)$ occluded sequences. In line with previous studies [13-15, 17], ANOVA showed a large main effect of occlusion on accuracy, $\mathrm{F}(1,34)=110, \mathrm{p}<.0001$, and significantly higher accuracy in experts, $\mathrm{F}(2,34)=6.8, \mathrm{p}<.005$. Experts showed a non-significant trend for greater relative accuracy on early occluded sequences, $F(2,34)=2.9, p=.064$. The competitive level 
correlated positively with mean accuracy on task, $r=.46, p<.005$ and the number of hours training per week, $\mathrm{r}=.38, \mathrm{p}<.05$, but not with years since first game, $\mathrm{r}=.099$, n.s.

In order to evaluate the influence of expertise and temporal occlusion on the BOLD response, a second-level, regions of interest ROI analysis was carried out using MarsBaR [21]. For each participant, the effect size for each relevant t-contrast was quantified as a contrast value in 6 symmetrical left and right hemisphere pairs of $8 \mathrm{~mm}$ radius spherical ROI, located on the basis of independent data [Experiment 1 and ref. 5]. For each ROI and each individual, contrast values for two t-contrasts, late-mctrl and early-mctrl, were entered into a 2 occlusion level (within) x 2 hemispheres (between) $\mathrm{x}$ 3 expertise (between) mixed ANOVA. Results are shown in Table 2. There was a significantly larger response to early occluded blocks in all ROIs. Significantly greater activation in experts was found in dorsolateral, ventrolateral and medial frontal cortex. An interaction between occlusion level and expertise was found for ventrolateral and medial frontal cortex with experts showing greater relative levels of activation for earlymctrl compared with late-mctrl. However there was no corresponding interaction in the posterior cortical ROIs: BA40, superior temporal sulcus or middle temporal visual area.

Table 2 near here

\section{Discussion}

The aim of Experiment 1 was to identify brain regions activated in a badminton anticipation task when contrasted with a control condition in which the opponent's general body movements were observed. The brain areas activated in this t-contrast correspond with those identified in previous research as important for the analysis of observed, goal-directed actions [1-5]. In a further control experiment to establish task specificity, the dynamics of the stimuli were exactly matched by subjecting half of the 
stimuli to a left-right reversal, but a visuospatial discrimination left-right orientation was substituted for the prediction of shot direction. The visuospatial task did not activate substantial parts of the action observation network in parietal and frontal cortex, despite using near-identical stimuli. There was some overlap in the activations produced in posterior temporal cortex by the two tasks, but peaks of activity were distinct.

The role of expertise and temporal occlusion were examined in Experiment 2. In line with previous research it was established that accuracy on the anticipation task correlated with playing expertise level as defined by current competitive standard [1315, 17]. Following from Experiment 1 and the published literature, a number of a priori regions of interest were selected. Responses were greater for the early display occlusions, i.e., those requiring greater use of anticipation to predict stroke direction from pre-contact body kinematics rather than post-contact shuttle flight. This may reflect the greater perceptual difficulty of the early occlusion blocks, such that more resources are allocated to those brain areas that are analysing body movements [1-4]. Effects specific to expertise appeared only in a subset of these areas: dorsolateral premotor, ventrolateral frontal and medial frontal cortex. Wherever there was a significant occlusion $\mathrm{x}$ expertise interaction it always took the form of greater activation in experts than novices for early occlusion sequences.

Expert badminton players thus exhibit greater activity than do novices in a set of brain areas integral to action observation, imagery and execution, under conditions in which they are required to anticipate shot direction. However, the relationship between expertise and the increased BOLD response is not wholly explained by accuracy scores, since the BOLD response is also greater on the less accurate, early occlusion condition. There appear to be two processes at play: early occlusion increases the level of attention 
for all participants, resulting in increased activation across both posterior and anterior components of the action observation network. Experts, however, show an additional greater relative increase than novices in anterior components of the network, previously associated with the preparation and control of responses [22]. Thus, in agreement with recent electromyographic and TMS experiments on anticipation in basketball [17], experts may not only detect early anticipatory cues, but also prepare task-appropriate motor responses on the basis of early pick-up of anticipatory cues from the opposing player's body movements.

\section{Conclusion}

In participants making anticipatory predictions from video clips of an opponent's play, activation was seen in a network of brain areas previously associated with the observation, understanding and preparation of human action. For all observers, sequences requiring a focus on early body kinematics produced stronger activation. Expert sports players showed enhanced activation, especially for early parts of the action sequence, in frontal lobe constituents of the network. 


\section{References}

1. Decety J, Grèzes J. Neural mechanisms subserving the perception of human actions. Trends Cogn Sci 1999; 3: 172-178

2. Grèzes J, Decety J. Functional anatomy of execution, mental simulation, observation and verb generation of actions: a meta-analysis. Hum Brain Mapp 2001; 12: 1-19

3. Rizzolatti G, Craighero L The mirror-neuron system. Annu Rev Neurosci 2004; 27: 169-192.

4. Morin $\mathrm{O}$, Grèzes J. What is "mirror" in the premotor cortex? A review. Neurophysiol Clin 2008; 38: 189-195.

5. Wright MJ, Jackson RC. Brain regions concerned with perceptual skills in tennis: an fMRI study. Int J Psychophysiol 2007; 63: 214-220

6. Vogt S, Buccino G, Wohlschläger AM, Canessa N, Shah NJ, Zilles K, et al. Prefrontal involvement in imitation learning of hand actions: effect of practice and expertise. Neuroimage 2007; 37: 1371-1383.

7. Guillot A, Collet C, Nguyen VA, Malouin F, Richards C, Doyon J. Functional neuroanatomical networks associated with expertise in motor imagery. Neuroimage 2008; 41: 1471-1483.

8. Landau S, D'Esposito M. Sequence learning in pianists and nonpianists: an fMRI study of motor expertise. Cogn Affect Behav Neurosci 2006; 6: 246-259. 
9. Calvo-Merino B, Glaser DE, Grèzes J, Passingham RE, Haggard P. 2005 Action observation and acquired motor skills: an fMRI study with expert dancers. Cereb Cortex 2005; 15: 1243-1249.

10. Lyons IM, Mattarella-Micke A, Cieslak M, Nusbaum HC, Small SL, Beilock SL. The role of personal experience in the neural processing of action-related language. Brain Lang in press.

11. Milton J, Solodkin A, Hlustik P, Small SL. The mind of expert motor performance is cool and focused. Neuroimage 2007; 35: 804-813.

12. Kim J, Lee HM, Kim WJ, Park HJ, Kim SW, Moon DH, et al. Neural correlates of pre-performance routines in expert and novice archers. Neurosci Lett 2008; 445: 236-241.

13. Abernethy B, Zawi K, Jackson RC. Expertise and attunement to kinematic constraints. Perception 2008; 6: $931-948$.

14. Abernethy B. Expertise, visual search and information pick-up in squash. Perception 1990; 19: 63-77.

15. Abernethy B, Gill D, Parks SL, Packer ST. Expertise and the perception of kinematic and situational probability information. Perception 2001; 30: 233 252.

16. Huys R, Smeeton NJ, Hodges N, Williams MA. On the dynamic information underlying visual anticipation skill. Percept Psychophys 2008; 70: 1217-1234

17. Aglioti SM, Cesari P, Romani M \& Urgesi C. Action anticipation and motor resonance in elite basketball players. Nat Neurosci 2008; 11: 1109-1116.

18. Smith AT, Wall MB, Williams AL, Singh KD. Sensitivity to optic flow in human cortical areas MT and MST. Eur J Neurosci 2006; 23: 561-569. 
19. Maldjian JA, Laurienti PJ, Burdette JB. Kraft, RA. An automated method for neuroanatomic and cytoarchitectonic atlas-based interrogation of MRI data sets. Neuroimage 2003; 19: 1233-1239.

20. Lancaster JL, Summerlin JL, Rainey L, Freitas CS, Fox PT. The Talairach Daemon, a database server for Talairach atlas labels. Neuroimage 1997; 5: S633.

21. Brett M, Anton JL, Valabregue R, Poline JB. Region of interest analysis using an SPM toolbox; 8th International Conference on Functional Mapping of the Human Brain; Sendai, Japan. 2002.

22. Heekeren HR, Marrett S, Ungerleider LG. The neural systems that mediate human perceptual decision-making. Nat Rev Neurosci 2008; 9: 467-479.

Supplemental Digital Content: Video.

Example_Pix_grey_mp4.mp4 
Figure 1

Click here to download high resolution image

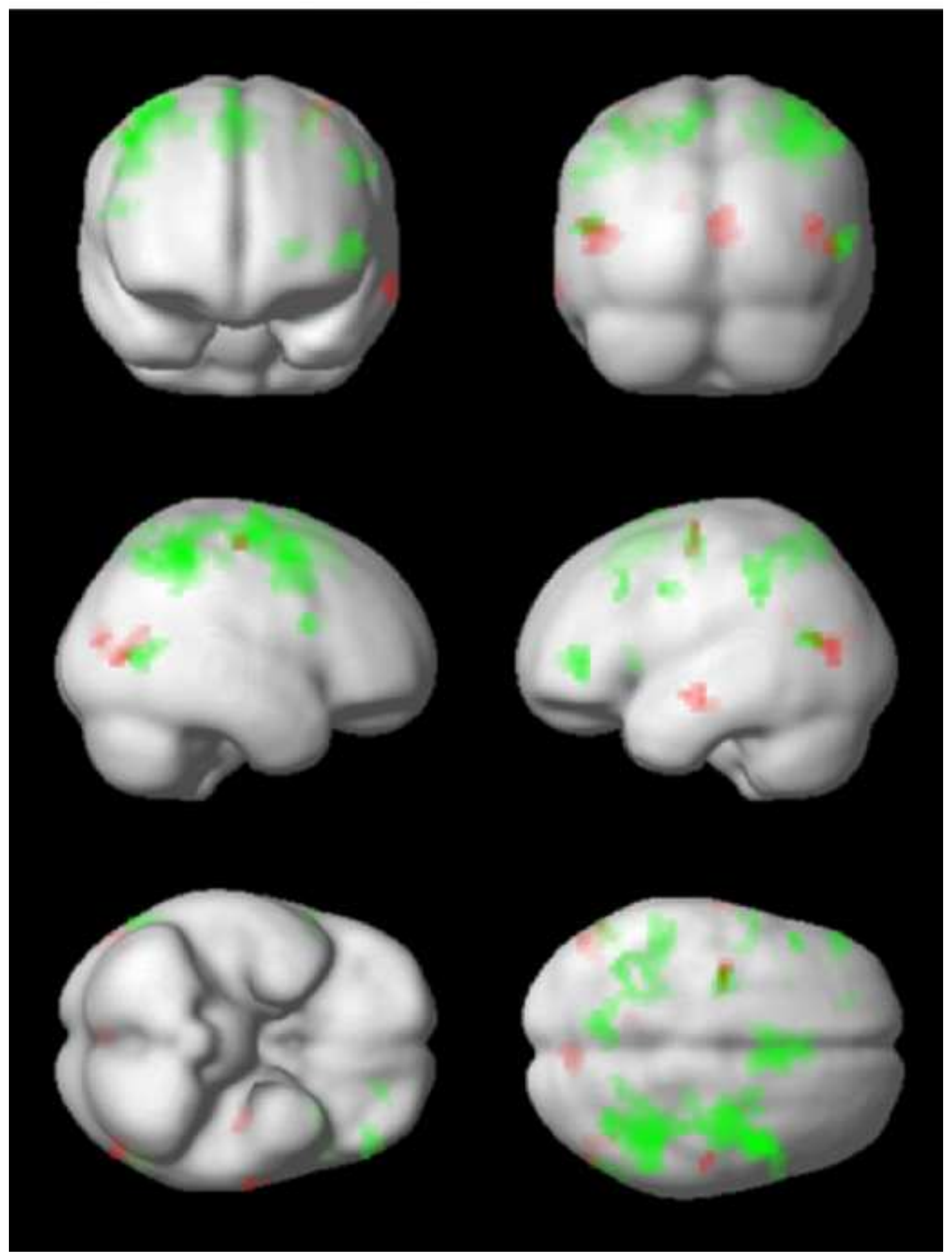


Table 1. Peak voxel of principal clusters activated in Experiment 1 (random effects).

\begin{tabular}{|c|c|c|c|c|c|c|c|}
\hline \multirow[b]{2}{*}{ Area } & \multirow[b]{2}{*}{ BA } & \multicolumn{2}{|c|}{$\begin{array}{l}\text { Anticipation task } \\
\text { shots - mctrl }\end{array}$} & \multicolumn{3}{|c|}{$\begin{array}{l}\text { Visuospatial task } \\
\text { shots - mctrl }\end{array}$} & \multirow[b]{2}{*}{$\mathrm{Z}$} \\
\hline & & $\mathrm{x}, \mathrm{y}, \mathrm{z}$ & $\begin{array}{l}\text { clu } \\
\text { ster }\end{array}$ & $\mathrm{Z}$ & $\mathrm{x}, \mathrm{y}, \mathrm{z}$ & $\begin{array}{l}\text { clu } \\
\text { ster }\end{array}$ & \\
\hline $\begin{array}{l}\text { Inferior parietal } \\
\text { lobule }\end{array}$ & $\begin{array}{l}40 \\
40\end{array}$ & $\begin{array}{c}-54-4236 \\
42-4554\end{array}$ & $\begin{array}{l}230 \\
806\end{array}$ & $\begin{array}{l}4.16 \\
4.92\end{array}$ & & & \\
\hline $\begin{array}{l}\text { Dorsolateral } \\
\text { premotor }\end{array}$ & $\begin{array}{l}6 \\
6\end{array}$ & $\begin{array}{l}-30-1257 \\
48651\end{array}$ & 42 & $\begin{array}{l}3.6 \\
5.09\end{array}$ & $\begin{array}{c}-27-1260 \\
54-1857\end{array}$ & $\begin{array}{l}15 \\
6\end{array}$ & $\begin{array}{l}3.48 \\
3.15\end{array}$ \\
\hline $\begin{array}{l}\text { Dorsolateral } \\
\text { prefrontal }\end{array}$ & $\begin{array}{l}10 \\
46\end{array}$ & -21483 & 15 & 4.59 & & & \\
\hline Medial frontal & 6,32 & 61260 & 200 & 4.52 & & & \\
\hline Precuneus & $\begin{array}{l}7 \\
24\end{array}$ & $-9-6954$ & & 4.28 & $-12-5724$ & 11 & 3.25 \\
\hline $\begin{array}{l}\text { Ventrolateral } \\
\text { frontal }\end{array}$ & $\begin{array}{l}45 \\
44\end{array}$ & $\begin{array}{l}-45420 \\
511221\end{array}$ & $\begin{array}{l}38 \\
20\end{array}$ & $\begin{array}{l}4.17 \\
4.38\end{array}$ & & & \\
\hline $\begin{array}{l}\text { Temporal - } \\
\text { occipital }\end{array}$ & $\begin{array}{l}39,19 \\
39,19\end{array}$ & $\begin{array}{c}-51-6615 \\
60-663\end{array}$ & $\begin{array}{l}23 \\
26\end{array}$ & $\begin{array}{l}3.76 \\
4.32\end{array}$ & $\begin{array}{l}-48-759 \\
45-6318\end{array}$ & $\begin{array}{l}43 \\
31\end{array}$ & $\begin{array}{l}3.25 \\
3.13\end{array}$ \\
\hline Middle frontal & 8 & -482433 & 10 & 4.29 & & & \\
\hline $\begin{array}{l}\text { Insula/frontal } \\
\text { operculum }\end{array}$ & 13,47 & -39150 & 12 & 4.17 & & & \\
\hline Mid temporal & 21 & & & & $-66-15-15$ & 15 & 3.76 \\
\hline Hippocampus & & & & & $-39-21-15$ & 14 & 3.53 \\
\hline Occipital & 18 & & & & $6-8115$ & 52 & 3.32 \\
\hline
\end{tabular}

anticipation task: $P<.001$ uncorrected, cluster size $>10$;

visuospatial task: $P<.005$ uncorrected, cluster size $>5$. 
Table 2. Experiment 2: ANOVA on group data for 7 ROIs.

\begin{tabular}{|c|c|c|c|c|c|c|c|}
\hline & $\mathrm{BA}$ & $\begin{array}{l}x \\
y \\
z\end{array}$ & occlusion & expertise & $\begin{array}{l}\text { hemi- } \\
\text { sphere }\end{array}$ & $\begin{array}{l}\text { occlusion } \\
\mathrm{x} \\
\text { expertise }\end{array}$ & $\begin{array}{l}\text { occlusion } \\
\text { x hemi- } \\
\text { sphere }\end{array}$ \\
\hline $\begin{array}{l}\text { Dorsolateral } \\
\text { premotor }\end{array}$ & 6 & $\begin{array}{l} \pm 54 \\
12 \\
22\end{array}$ & $\begin{array}{l}F(1,68) \\
=5.8 \\
P<.05\end{array}$ & $\begin{array}{l}F(2,68) \\
=6.3 \\
P<.005\end{array}$ & n.s. & n.s. & n.s. \\
\hline $\begin{array}{l}\text { Ventrolateral } \\
\text { frontal }\end{array}$ & 44 & $\begin{array}{l} \pm 56 \\
24 \\
0 \\
\end{array}$ & $\begin{array}{l}F(1,68) \\
=61.7, \\
P<.0001\end{array}$ & $\begin{array}{l}F(2,68) \\
=7.1, \\
P<.005\end{array}$ & $\begin{array}{l}F(1,68) \\
=4.4, \\
P<.05\end{array}$ & $\begin{array}{l}F(2,68) \\
=10.0 \\
P<.0005\end{array}$ & n.s. \\
\hline $\begin{array}{l}\text { Medial } \\
\text { frontal }\end{array}$ & 8 & $\begin{array}{l} \pm 4 \\
18 \\
45\end{array}$ & $\begin{array}{l}F(1,68) \\
=13.9, \\
P<.0001\end{array}$ & n.s. & n.s. & $\begin{array}{l}F(2,68) \\
=9.5, \\
P<.0005\end{array}$ & n.s. \\
\hline $\begin{array}{l}\text { Medial } \\
\text { frontal }\end{array}$ & 9 & $\begin{array}{l} \pm 3 \\
30 \\
47\end{array}$ & $\begin{array}{l}F(1,68) \\
=35.9, \\
P<.0001\end{array}$ & $\begin{array}{l}F(2,68) \\
=9.9, \\
P<.0005\end{array}$ & n.s. & $\begin{array}{l}F(2,68) \\
=8.2 \\
P<.001\end{array}$ & n.s. \\
\hline $\begin{array}{l}\text { Inferior } \\
\text { parietal } \\
\text { lobule }\end{array}$ & 40 & $\begin{array}{l} \pm 53 \\
-42 \\
27\end{array}$ & $\begin{array}{l}F(1,68) \\
=12.7 \\
P<.005\end{array}$ & n.s. & n.s. & n.s. & n.s. \\
\hline $\begin{array}{l}\text { Superior } \\
\text { temporal } \\
\text { sulcus }\end{array}$ & 39 & $\begin{array}{l} \pm 51 \\
-66 \\
15\end{array}$ & $\begin{array}{l}F(1,68) \\
=4.3 \\
P<.05\end{array}$ & n.s. & n.s. & n.s. & $\begin{array}{l}F(1,68) \\
=4.0 \\
P<.05\end{array}$ \\
\hline $\begin{array}{l}\text { Visual } \\
\text { motion } \\
\text { localiser }\end{array}$ & $\begin{array}{l}19 \\
39\end{array}$ & & $\begin{array}{l}F(1,34) \\
=48.8, \\
P<.0005\end{array}$ & n.s. & n.s. & n.s. & $\begin{array}{l}F(1,34) \\
=9.3, \\
P<.005\end{array}$ \\
\hline
\end{tabular}



We examined the effect of expertise on cortical activation during sports anticipation using fMRI. In Experiment 1, while recreational players predicted badminton stroke direction, the pattern of active clusters was consistent with a proposed perception-of-action network. This pattern was not replicated in a stimulus-matched, action-unrelated control task. In Experiment 2, players of three different skill levels anticipated stroke direction from clips occluded either $160 \mathrm{~ms}$ before or $80 \mathrm{~ms}$ after racquet-shuttle contact. Early-occluded sequences produced more activation than late-occluded overall, in most cortical regions of interest, but experts showed an additional enhancement in medial, dorsolateral and ventrolateral frontal cortex. Anticipation in open-skill sports engages cortical areas integral to observing and understanding others' actions; such activity is enhanced in experts. 